\title{
Rapid determination of iodine content in drinking water by isopropyl sensitization and inductively coupled plasma mass spectrometry (ICP-MS)
}

\author{
Yanxia Zeng ${ }^{1,2}$, Xiashi Zhu ${ }^{1 *}$ \\ ${ }^{1}$ Department of Chemical Engineering, Yangzhou University,Yangzhou City, Jiangsu Province, 225009, China \\ ${ }^{2}$ Institute of Marine Resource Development, Jiangsu Ocean University, Lianyungang City, Jiangsu Province, 222005, China)
}

\begin{abstract}
A subject for the rapid determination of iodine content in drinking water by isopropyl sensitization and ICP-MS was established. The samples were dissolved in $1 \%$ ammonia solution, ${ }^{127}$ I was selected as the mass number to be measured and ${ }^{159} \mathrm{~Tb}$ as an internal standard. At the same time, $4 \%(\mathrm{~V} / \mathrm{V})$ isopropanol was used to enhance aerosol gasification efficiency, $2 \% \mathrm{NH}_{3} \cdot \mathrm{H}_{2} \mathrm{O}$ was used to effectively eliminate memory effects of iodine by cleaning sample for 180 seconds. The results show that, the detection limits of iodine in this method are $0.007 \mathrm{mg} \cdot \mathrm{kg}^{-1}$ and it is superior to other literature. The standard curve has a good linear relationship and the recovery rates of testing rusults range are from $96.00 \%$ to $112.3 \%$. The content of iodine in standard substance water samples was determined by ICP-MS method. The iodine content in water samples from seven drinking water sources in Lianyungang area was analyzed between $14 \sim 21 \mu \mathrm{g} \cdot \mathrm{L}^{-1}$. It was in line with the allowable value of $10 \sim 300 \mu \mathrm{g} \cdot \mathrm{L}^{-1}$ of the sanitary standard for drinking water, suggesting that the iodine content of drinking water resources in Lianyungang area was in a safe range.
\end{abstract}

\section{Introduction}

Odine is closely related to the growth and metabolism of the human body. It is one of the trace elements with important biological effects. Lack, excessive or unbalanced intake of iodine can cause physiological abnormalities and lead to diseases. ${ }^{[1,2]}$ The iodine that the human body needs mainly comes from food and water ${ }^{[3]}$.Although most areas of the country are short of iodine or moderate in iodine, there are still about 30 million people in 11 provinces living in high water iodine environment ${ }^{[4]}$. At present, the commonly used method for determining water iodine content is cerium sulfate catalytic spectrophotometry ${ }^{[5]}$, but the detection range is narrow and the limitations are strong. There are many methods for measuring total iodine in water samples, most of which have a narrow detection range and cannot meet the requirements of high-iodine or lowiodine areas ${ }^{[6,7]}$. Lack of standard materials, low content, easy contamination of the matrix, and active and easy oxidation of iodine are the main difficulties in the determination of trace ultra-trace iodine in water.

Inductively coupled plasma mass spectrometry (ICPMS) is currently recognized as the best multi-element simultaneous analysis technology ${ }^{[8]}$, although the first ionization energy of non-metals such as bromine, iodine, and arsenic is somewhat high, such as the first ionization of iodine. It can be $10.45 \mathrm{eV}$, and there is only about $25 \%$ ionization in the instrument, but compared with other analytical methods, it still has a relatively high sensitivity ${ }^{[9]}$. At present, ICP-MS determination of iodine is mostly used to detect biological samples. For example, Vanhoeet al ${ }^{[10]}$ determine milk powder samples, Larsen et $\mathrm{al}^{[11]}$ determine food samples, Cox et $\mathrm{al}^{[12]}$ determine vegetable samples, Buchert et $\mathrm{al}^{[13]}$ determine milk samples, and Baumann et al ${ }^{[14]}$ determine fresh milk, etc., but there are only a few reports on the detection of iodine in water ${ }^{[15]}$.

This experiment established for the first time the method of alkalization of ammonia water medium combined with isopropanol sensitization signal, and inductively coupled plasma mass spectrometry to directly determine trace iodine in drinking water sources. The iodine of water samples of seven drinking water sources in Lianyungang area was analyzed with satisfactory results. 


\section{Experimental part}

\subsection{Instruments and reagents}

electronic balance BS210S (Beijing Sartorius Balance Co., Ltd.); ICP-MS inductively coupled plasma mass spectrometer (ICP-MS) (Bruker ICP-MS M90); Sc standard solution (purchased from the National Standard Material Center);

Iodine standard solution (purchased from the National Standard Material Center); Watsons distilled water (purchased by Lotte Mart, Cangwu Road, Xinpu District, Lianyungang); nitric acid (merk nitric acid, Germany); iodine standard solution (purchased from the National Standard Material Center); ammonia (excellent grade pure, Sinopharm Chemical Reagent Co., Ltd.)

\subsection{Instrument}

The working conditions of the inductively coupled plasma mass spectrometer are shown in Table 1.

Table 1. Working parameter of ICP-MS.

\begin{tabular}{lccc}
\hline Working parameter & set value & Working parameter & value \\
\hline $\begin{array}{c}\text { Plasma flow } \\
\text { velocity/L/min }\end{array}$ & 16.5 & Sampling depth $/ \mathrm{mm}$ & 6.5 \\
$\begin{array}{c}\text { Auxiliary gas flow } \\
\text { velocity/L/min }\end{array}$ & 2.00 & Peristaltic pump rate/ rpm & 4 \\
$\begin{array}{c}\text { Protective gas flow } \\
\text { velocity/L/min } \\
\text { Atomizer }\end{array}$ & 0.20 & Stable delay time/s & 10 \\
velocity/L/min & residence time/ ms & 10000 \\
$\begin{array}{c}\text { Scanning times } \\
\text { /times }\end{array}$ & 1.00 & Sample interval cleaning & time/s \\
$\begin{array}{c}\text { Analysis element } \\
\text { Radiofrequency } \\
\text { power/ } \mathrm{kW}\end{array}$ & 50 & Total acquisition time/s & 60 \\
\hline
\end{tabular}

\subsection{Water sample collection and processing}

Water samples from water sources were taken in cities and towns surrounding Lianyungang City. The locations of the sampling points are shown in Table 2. Use a water collector to take a water sample from below the water surface, put it into a $500 \mathrm{~mL}$ plastic bottle, and bring it back to the laboratory refrigerator for storage. Before use, the original water sample is centrifuged and filtered, and then acidified or alkalized.
2.3.1 Acidification treatment. Accurately pipette $98.00 \mathrm{~mL}$ of filtered water sample and add nitric acid to a $100.00 \mathrm{~mL}$ PE volumetric flask to be tested. The final water sample contains $2 \%$ nitric acid.

2.3.2 Alkalization treatment. Accurately pipette $99.00 \mathrm{~mL}$ of filtered water sample and add ammonia water to a $100.00 \mathrm{~mL}$ volumetric flask to be tested. The final water sample contains $1 \%$ ammonia water.

2.3.3 Direct treatment. Take $100 \mathrm{ml}$ of filtered water for testing.

Table 2. Coordinates of sampling Points.

\begin{tabular}{|c|c|c|c|c|c|c|}
\hline place & Qiantan & $\begin{array}{c}\text { Waterworks of } \\
\text { Maokou }\end{array}$ & $\begin{array}{c}\text { Waterworks of } \\
\text { Haizhou }\end{array}$ & $\begin{array}{c}\text { Waterworks of } \\
\text { West Ganyu } \\
\text { City }\end{array}$ & Dayangzhuang & Siying \\
\hline coordinate & $119^{\circ} 13^{\prime} 7.93^{\prime \prime E}$ & $119^{\circ} 13^{\prime} 7.84^{\prime \prime} \mathrm{E}$ & $119^{\circ} 13^{\prime} 7.05^{\prime \prime E}$ & $119^{\circ} 13^{\prime} 7.47^{\prime \prime} \mathrm{E}$ & $119^{\circ} 13^{\prime} 7.47^{\prime \prime} \mathrm{E}$ & $119^{\circ} 13^{\prime} 7.47^{\prime \prime E}$ \\
\hline S & $34^{\circ} 36^{\prime} 45.39^{\prime \prime} \mathrm{N}$ & $34^{\circ} 36^{\prime} 44.82^{\prime \prime} \mathrm{N}$ & $34^{\circ} 36^{\prime} 45.77^{\prime \prime N}$ & $34^{\circ} 36^{\prime} 44.63^{\prime \prime} \mathrm{N}$ & $34^{\circ} 36^{\prime} 44.63^{\prime \prime N}$ & $34^{\circ} 36^{\prime} 44.63^{\prime \prime} \mathrm{N}$ \\
\hline
\end{tabular}

\section{Results and discussion}

\subsection{Sample medium selection}

The signal intensity of iodine in the water sample is related to the medium. In the experiment, the iodine signal intensity and RSD\% in the water sample were used as indicators, and ammonia water and nitric acid were used as the media respectively to compare the effects of the two media on the iodine signal in the water. The results are shown in Figure 1. 


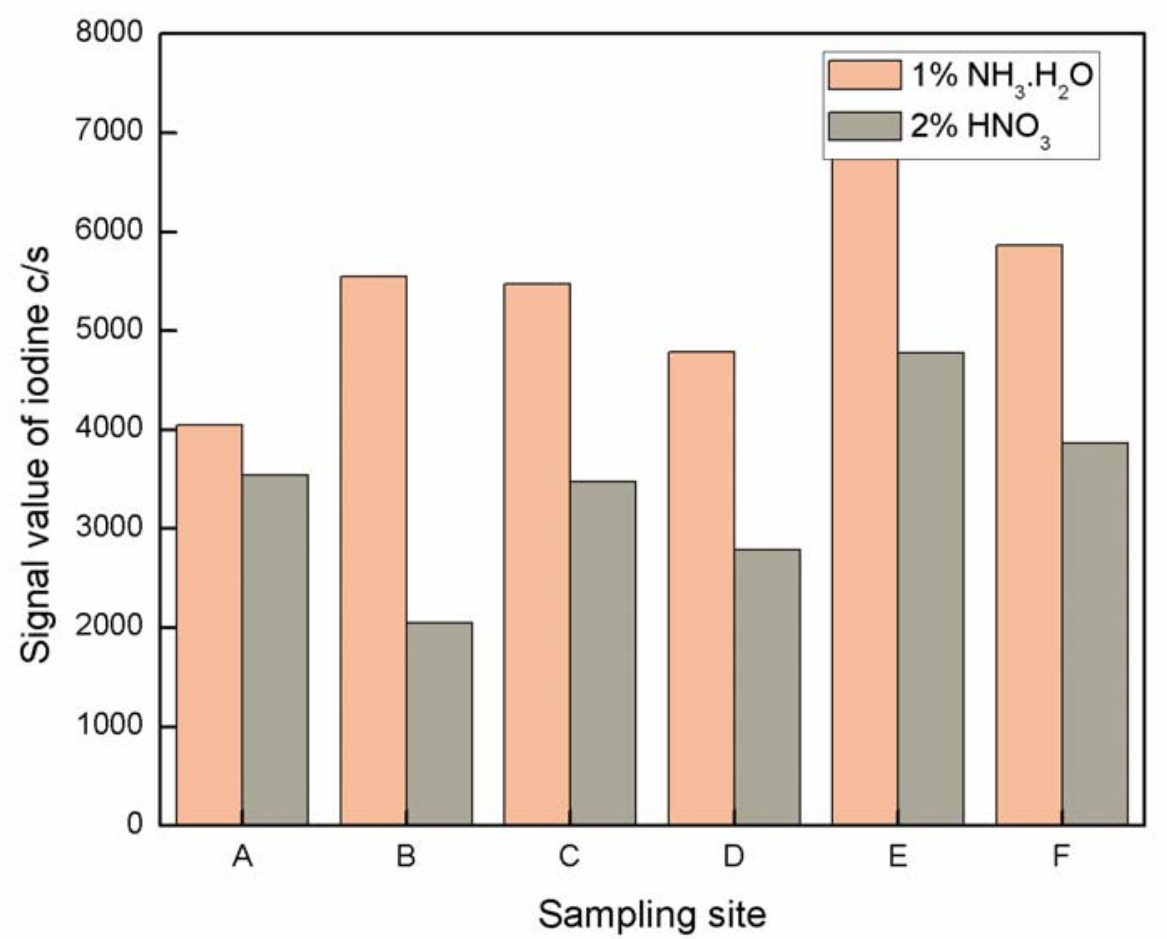

Fig. 1 signal value of iodine in $1 \% \mathrm{NH}_{3} \cdot \mathrm{H}_{2} \mathrm{O}$ vs $2 \% \mathrm{HNO}_{3}$ medium

It can be seen from the figure that the signal intensity of ${ }^{127} \mathrm{I}$ in the ammonia medium is almost double the value of nitric acid. The RSD\% value of the water sample in $1 \%$ ammonia medium is between $0 \%$ and $5 \%$, while the $\mathrm{RSD} \%$ value in the $2 \%$ nitric acid medium is between $20 \%$ and $41 \%$. The results indicate the signal stability and the signal sensitivityof iodine are better in ammonia medium than in nitric acid medium.

\section{2 sensitization}

According to the literature report, adding a certain amount of ethanol to the solution by ICP-MS can enhance the signal of iodine. The signal enhancement of iodine by methanol, ethanol and isopropanol in the concentration range of $1 \% \sim 5 \%$ was investigated in the presence of $1 \%$ ammonia with the iodine signal value of the concentration of $20 \mu \mathrm{g} \cdot \mathrm{L}-1 \quad 127 \mathrm{I}$ as an index.The results are shown in figure 2 .

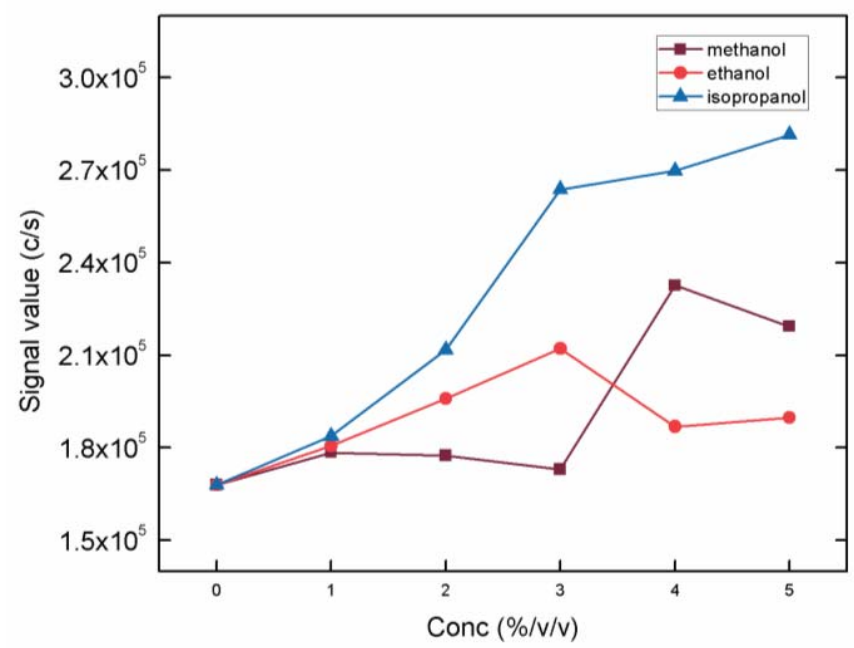

Fig.2 Signal value of $20 \mu \mathrm{g} \cdot \mathrm{L}^{-1}$ iodine under different alcohols media 
As can be seen from the diagram, adding a small amount of methanol, ethanol, isopropanol can improve the signal sensitivity of iodine. Compared with several alcohols, the signal increase of isopropanol was the most obvious change with the concentration, and the iodine signal value was the largest when the content of isopropanol increasd to $4 \%(\mathrm{~V} / \mathrm{V})$.

\section{3 selection of internal standard}

If the sample contains internal standard elements, it will interfere with the calibration of the analysis results, and if the concentration of internal standard elements is increased to counteract the interference, the correction of low signal value will be lost because of the high signal value of internal standard. ${ }^{[16]}$ In order to eliminate matrix effect and to correct the influence of instrument response variation on the determination, internal standard elements such as ${ }^{159} \mathrm{~Tb}$ 或 ${ }^{89} \mathrm{Y}$ are needed.The results showed that good results were obtained when the concentration of $5.0 \mu \mathrm{g} \cdot \mathrm{L}^{-1}$ terbium was added online as internal standard.Its internal standard signal value is about $400000 \mathrm{c} / \mathrm{s}$, which can effectively compensate for the change of instrument condition in the testing process.

\section{4 optimization of cleaning media and cleaning time}

Some problems, such as serious memory effect, great fluctuation of Analytical Signal, poor accuracy and precision, often occur in the determination of iodine in samples by ICP-MS. When iodine is determined in the form of iodide in $\mathrm{HNO}_{3}$ medium, the analytical error can be as high as $750 \%{ }^{[16]}$ The main reason is that the determination of iodine by ICP-MS is complicated by the different forms of iodine, volatility and pollution. In order to reduce the memory effect of iodine, we tried to choose a suitable cleaning solution to clean the injection system. Li Bing et $\mathrm{al}^{[9]}$ reported that the choice of dilute $\mathrm{NH}_{3} \cdot \mathrm{H}_{2} \mathrm{O}$ cleaning injection system significantly reduced the memory effect of iodine and bromine. The $100 \mu \mathrm{g} \cdot \mathrm{L}^{-1}$ iodine standard solution was chosen as the test solution, and the signal intensity of $100 \mu \mathrm{g} \cdot \mathrm{L}^{-1}$ iodine standard solution in pure water is about $4.0 \times 10^{6} \mathrm{c} / \mathrm{s}$. The cleaning effect and cleaning time of $2 \% \mathrm{HNO}_{3}$, pure water and $1 \% \sim 5 \% \quad \mathrm{NH}_{3} \cdot \mathrm{H}_{2} \mathrm{O}$ were compared respectively. The signal intensity of $100 \mathrm{ppb}$ iodine standard solution cleaned by different cleaning solution changed with time. The cleaning effect and cleaning time of $2 \% \mathrm{HNO} 3$, pure water and $1 \% \sim 5 \% \mathrm{NH}_{3} \cdot \mathrm{H}_{2} \mathrm{O}$ were compared respectively, and the signal intensity of $100 \mathrm{ppb}$ iodine standard solution cleaned by different cleaning solution was changed with time.The results of different cleaning solutions are shown in figure 3.

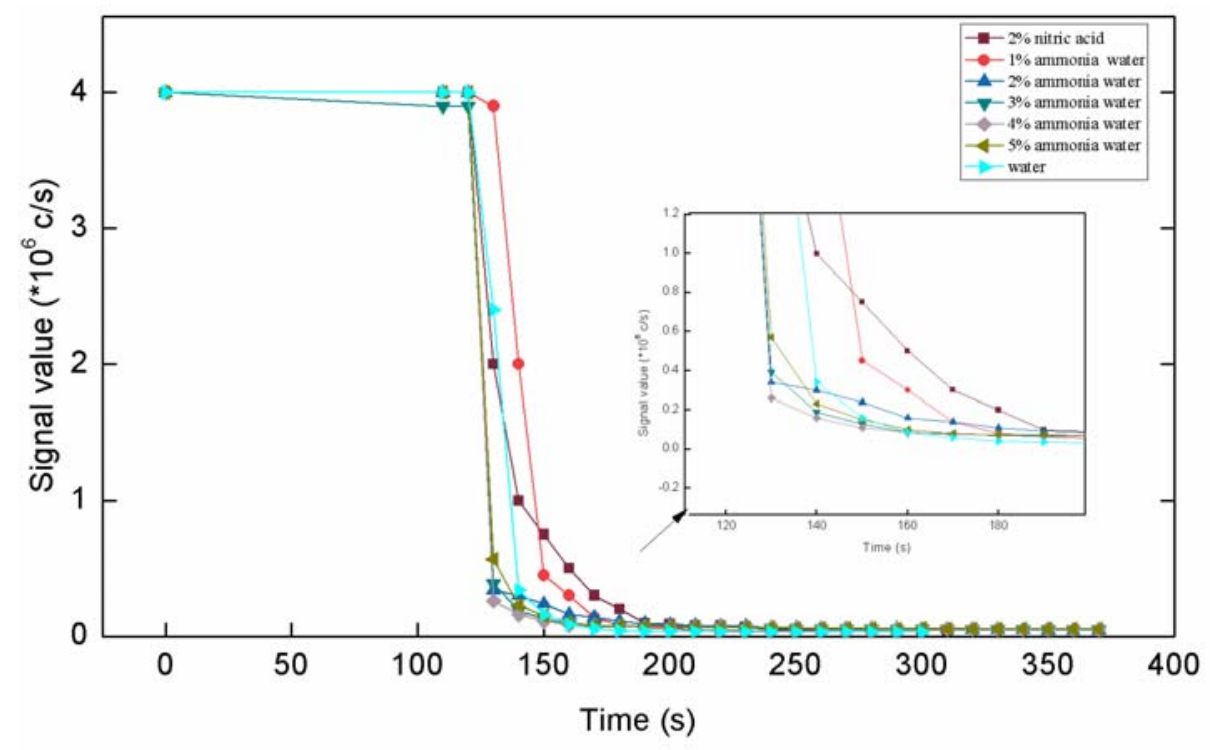

Fig. 3 cleaning effect under different cleaning solutions

As can be seen from Fig.2, all cleaning solutions above 200 seconds can reduce the signal to the value of the blank signal.5\%(V/V) ammonia water and $2 \%(\mathrm{~V} / \mathrm{V})$ nitric acid were the slowest, pure water and $1 \%$ $(\mathrm{V} / \mathrm{V}) \mathrm{NH}_{3} \cdot \mathrm{H}_{2} \mathrm{O}$ were the second, and $2 \% \sim 5 \%$ (V/V) $\mathrm{NH}_{3} \cdot \mathrm{H}_{2} \mathrm{O}$ could make the iodine signal decrease rapidly after 130 seconds time cleaning.In the medium of blank ultra-pure water, the blank value of ammonia water is higher than that of nitric acid. It is inferred that the matrix of ammonia water itself causes some interference, which may explain why the cleaning effect is not improved synchronously after the concentration of ammonia water increases. The results showed that When $2 \%(\mathrm{~V} / \mathrm{V})$ ammonia water was used to clean the injection system, the iodine signal value decreased to lower than $1.0 \times 10^{5} \mathrm{c} / \mathrm{s}$ when the cleaning time reached 180 seconds when the injection tube was inserted into the cleaning liquid, after that, the signal value which changes with time decreases slowly to the size of the blank signal value $(\sim 0.5 \times 105 \mathrm{c} / \mathrm{s})$. 


\section{5 optimization of analytical performance}

\subsubsection{Standard working curve}

Preparation of standard solution: $0,1.0 \mu \mathrm{g} \cdot \mathrm{L}^{-1}, 2.0 \mu \mathrm{g} \cdot \mathrm{L}^{-}$

${ }^{1}, 4.0 \mu \mathrm{g} \cdot \mathrm{L}^{-1}, 8.0 \mu \mathrm{g} \cdot \mathrm{L}^{-1}, 10 \mu \mathrm{g} \cdot \mathrm{L}^{-1}$ standard solutions were prepared with $100 \mu \mathrm{g} \cdot \mathrm{L}^{-1}$ iodine standard solution as mother solution and $1 \%(\mathrm{~V} / \mathrm{V})$ ammonia as medium, after washing with $2 \%(\mathrm{~V} / \mathrm{V})$ ammonia for 180 seconds, the working curve was drawn as shown in figure 4 .

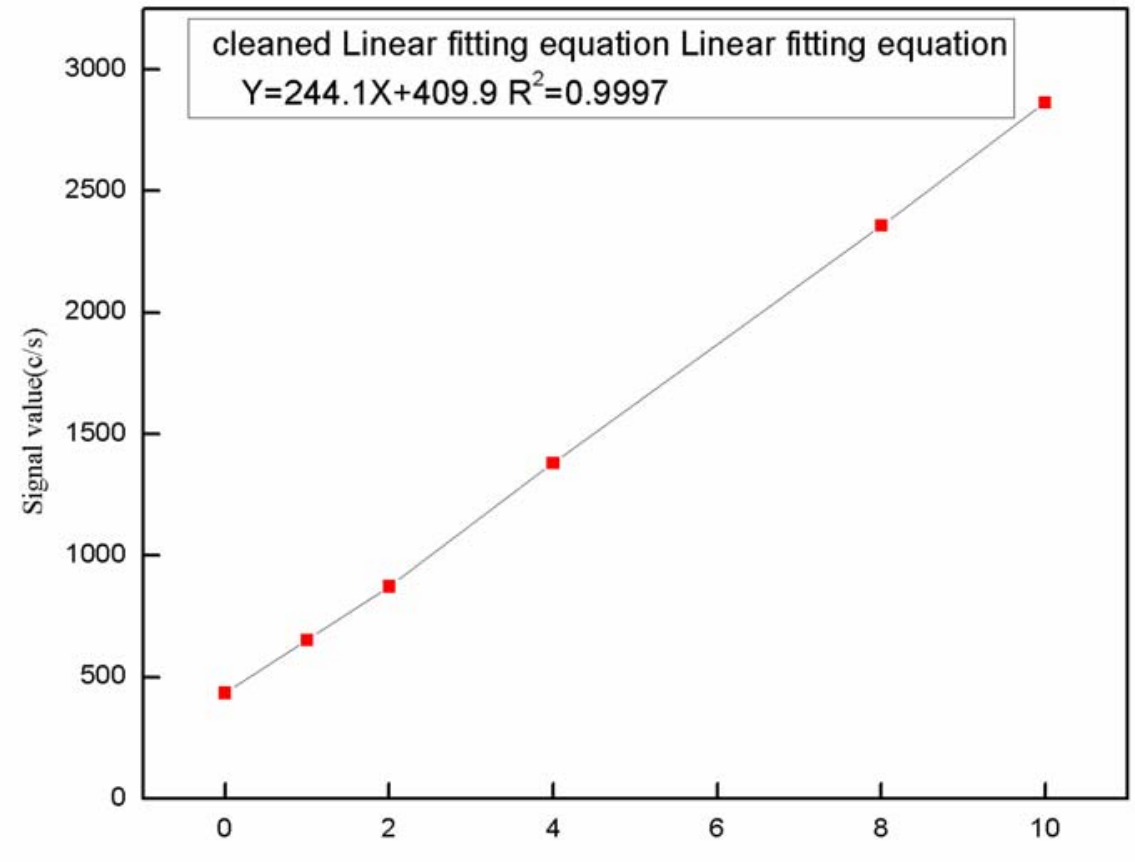

Fig.4 Signal concentration working curve of iodine

As can be seen from the figure 4, the Correlation Coefficient of the iodine standard liquid correlation curve is above the $0.999\left(\mathrm{R}^{2}=0.9997\right)$, which meets the linear requirement.

\subsection{2 method detection limit}

It was reported that Zuo Shumei et al ${ }^{[17]}$ used $2 \%(V / V)$ nitric acid as the medium to determine the iodine content in water samples and the lowest detection limit reached to $0.018 \mu \mathrm{g} \cdot \mathrm{L}^{-1}$. Li Bing et $\mathrm{Al}{ }^{[9]}$ used $1 \%(\mathrm{~V} / \mathrm{V})$ ammonia as the medium to determine the iodine content in geological samples, also the lowest detection limit reached to $0.018 \mu \mathrm{g} \cdot \mathrm{L}-1$.The detection limit $(\mathrm{n}=11)$ of the method is $0.007 \mu \mathrm{g} \cdot \mathrm{L}^{-1}$, which is lower than the method reported in the literature.

\section{6 recovery}

$50 \mu \mathrm{g} \cdot \mathrm{L}^{-1}$ iodine standard solution was used as the standard solution, $95.00 \mathrm{ml}$ of the test solution was transferred to $100.00 \mathrm{ml}$ volumetric flask, $5.00 \mathrm{ml}$ standard solution was added, and then mixed thoroughly. The results are shown in Table 3 .

Table 3. Recovery test of iodine.

\begin{tabular}{|c|c|c|c|c|c|}
\hline Element & $\begin{array}{c}\text { Source of water } \\
\text { sample }\end{array}$ & $\begin{array}{l}\text { Background value } \\
/ \mu \mathrm{g}\end{array}$ & Scalar addition/ $/ \mu \mathrm{g} \mathrm{H}$ & Recovery value/ $\mu \mathrm{g}$ & Recovery rate $/ \%$ \\
\hline \multirow{6}{*}{${ }^{127} \mathrm{I}$} & Qiantan & 1.416 & 0.300 & 1.744 & 109.3 \\
\hline & $\begin{array}{l}\text { Waterworks of } \\
\text { Maokou }\end{array}$ & 1.996 & 0.300 & 2.312 & 105.3 \\
\hline & $\begin{array}{c}\text { Waterworks of } \\
\text { Haizhou }\end{array}$ & 2.017 & 0.300 & 2.341 & 108.0 \\
\hline & $\begin{array}{l}\text { Waterworks of } \\
\text { West Ganyu City }\end{array}$ & 1.686 & 0.300 & 2.023 & 112.3 \\
\hline & Dayangzhuang & 2.399 & 0.300 & 2.687 & 96.00 \\
\hline & Siying & 2.049 & 0.300 & 2.378 & 109.6 \\
\hline
\end{tabular}


The recovery rate of iodine content in different samples was between $96.0 \%$ and $112.3 \%$, which was in accordance with GB/T23942-2009(80\% 120\%).

\subsection{Comparison of test methods}

The iodine content in water was determined by the method of this experiment and the national standard method respectively with the iodine standard substance Gbw09113 as the analysis sample. The results are shown in Table 4.

Table 4. The iodine content of each sample is shown in the following figure $\left(\mu \mathrm{g} \cdot \mathrm{L}^{-1}\right)$.

\begin{tabular}{|c|c|c|c|c|c|c|}
\hline $\begin{array}{l}\text { Determination } \\
\text { frequency }\end{array}$ & 1 & 2 & 3 & 4 & 5 & 6 \\
\hline $\begin{array}{l}\text { National Standard } \\
\text { method } * / \mu \mathrm{g} \cdot \mathrm{L}^{-1}\end{array}$ & 10.5 & 10.2 & 9.9 & 8.9 & 8.6 & 9.2 \\
\hline This test $/ \mu \mathrm{g} \cdot \mathrm{L}^{-1}$ & 10.1 & 10.3 & 9.8 & 9.5 & 8.8 & 8.9 \\
\hline $\begin{array}{l}\text { Allowable range of } \\
\text { certified reference } \\
\text { material } / \mu \mathrm{g} \cdot \mathrm{L}^{-1}\end{array}$ & \multicolumn{6}{|c|}{$9.5 \pm 1.2$} \\
\hline
\end{tabular}

The experimental results show that the iodine content of the two methods is within the allowable range of the standard material, and can meet the actual determination of water samples. There was no significant difference between the two methods of t-test.

Table 5. Determination of iodine content in various water samples $\left(\mu \mathrm{g} \cdot \mathrm{L}^{-1}\right)$.

\begin{tabular}{|c|c|c|c|c|c|c|}
\hline Result & Qiantan & $\begin{array}{c}\text { Waterworks } \\
\text { Maokou }\end{array}$ & $\begin{array}{c}\text { Waterworks o } \\
\text { Haizhou }\end{array}$ & $\begin{array}{c}\text { Waterworks of } \\
\text { West Ganyu } \\
\text { City }\end{array}$ & f & Siying \\
\hline Content $/ \mu \mathrm{g} \cdot \mathrm{L}^{-1}$ & 14.0 & 20.2 & 20.4 & 16.9 & 24.4 & 20.7 \\
\hline $\mathrm{RSD} / \%$ & 2.6 & 3.5 & 2.1 & 2.6 & 3.1 & 3.2 \\
\hline$* *$ & \multicolumn{6}{|c|}{$10 \sim 300$} \\
\hline
\end{tabular}

** 《Hygienic Standard for drinking water》(GB5749-2006) Allowable iodine level

\section{8 sample determination}

The content of iodine in water sample was determined by inductively coupled plasma mass spectrometry (ICPMS) with ammonia solution-isopropanol sensitizing method. The results of the analyzed certified reference materials are within the allowable error range of the standard values $(\mathrm{RSD} \%<5 \%)$. The iodine content in water samples from seven drinking water sources in Lianyungang was analyzed. The iodine content was between 14.0 and $20.7 \mu \mathrm{g} \cdot \mathrm{L}^{-1}$, which was in accordance with the allowable value of $10 \sim 300 \mu \mathrm{g} \cdot \mathrm{L}^{-1}$ in the hygienic standard for drinking water.

Table 6. contrast of several determination methods of iodine.

\begin{tabular}{cccc}
\hline Experimental method & Medium & $\begin{array}{c}\text { Detection limit } \\
\left(\mu \mathrm{g} \cdot \mathrm{L}^{-1}\right)\end{array}$ & Linear range \\
$\begin{array}{c}\text { Sulfuric acid catalytic } \\
\text { Spectrophotometer }{ }^{[5]} \mu \mathrm{g} \cdot \mathrm{L}^{-1}\end{array}$ & 1\%Ammonia water & 1 & $1 \sim 1010 \sim 100$ \\
& $2 \%$ & & \\
$\mathrm{Li} \mathrm{Bing}{ }^{[9]} / \mu \mathrm{g} \cdot \mathrm{L}^{-1}$ & Nitric acid & 0.018 & \\
& & & \\
Zuo Shumei $^{[17]}$ & & 0.018 & $/$ \\
Guo Jingjing & & 0.15 & $0 \sim 500$
\end{tabular}




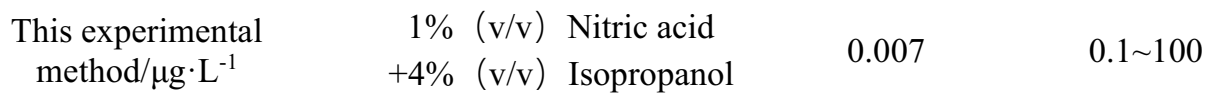

of other ions, for example, ${ }^{40} \mathrm{ArO}$ and ${ }^{40} \mathrm{CaO}$ can interfere with ${ }^{56} \mathrm{Fe},{ }^{46} \mathrm{CaOH}$ can interfere with ${ }^{63} \mathrm{Cu},{ }^{42} \mathrm{CaO}$ can

\section{Discuss}

The establishment of a rapid and accurate method for the determination of iodine in drinking water by ICP-MS is of great significance to the safety of iodine in drinking water.Our experimental method is superior to that reported in the literature in Detection limit of $0.007 \mu \mathrm{g} \cdot \mathrm{L}-$ 1 .Iodine is volatile, especially in acidic solutions to form volatile substances, such as HI or I2. Therefore, it is necessary to use TMAH, $\mathrm{NaOH}$ and $\mathrm{NH}_{4} \mathrm{OH}$ to stabilize iodine in solution.H. ISNARD et al ${ }^{[19]}$ compared the sensitivity, stability and elution time of iodine in $\mathrm{HNO}_{3}$, $\mathrm{NaOH}$ and TMAH. It was found that the signal sensitivity in $\mathrm{NaOH}$ and TMAH was better than that in HNO3.The effects of dilute nitric acid and dilute ammonia water on the signal intensity and the repeatability of the results were compared. The final results show that when $1 \%(\mathrm{v} / \mathrm{v}) \mathrm{NH}_{3} \cdot \mathrm{H}_{2} \mathrm{O}$ was used as the medium, the iodine signal in the water sample detected by ICP-MS was enhanced by about $1 / 3$, at the same time, the precision of repeated determination is greatly increased. It is inferred that the memory effect of point is decreased by inhibiting the volatilization of $\mathrm{HI}$ in iodine measurement under weak base condition. At the same time, the iodine signal in water was improved by Matrix, and the signal values of ethanol, methanol and glycerol were compared.In order to eliminate the memory effect of iodine further, the cleaning solution was selected, and it was determined that the memory effect of iodine could be effectively eliminated by adding $2 \%(\mathrm{v} / \mathrm{v}) \mathrm{NH}_{3} \cdot \mathrm{H}_{2} \mathrm{O}$ cleaning solution in 180 seconds between the standard sample, the sample to be tested and the sample, the linear relationship of serial standard solution can reach 0.9997. At the same time, the iodine signal in water was improved by Matrix, and the signal values of ethanol, methanol and glycerol were compared. It is confirmed that $4 \%$ isopropanol sensitizes the signal effectively. Common interference factors in the quantitative analysis by ICP-MS include the effects of acids, oxides and hydroxide, isotopes, complex ions and double charge ions. The influence of nitric acid on iodine may come from two aspects: When the sample solution contains nitric acid, phosphoric acid and sulfuric acid, it may form cations including $\mathrm{ArN}^{+}, \mathrm{PO}^{+}, \mathrm{ArP}^{+}$, $\mathrm{SO}^{+}, \mathrm{ArS}^{+} \mathrm{ClO}^{+}, \mathrm{ArC}^{+}$et al, these ions interfere with the determination of Si, Fe, Ti, Ni, Ga, Zn, Ge, V, Cr, As and Se.This interference can be eliminated by selecting another isotope ion of the analyte. In addition, iodine is unstable in acidic media.In ICP, the oxides of the metallic elements are completely dissociable, but near the sampling cone, the temperature is slightly lower and the residence time is longer, thus providing an opportunity for reoxidation. The strength ratio of $\mathrm{Ce}^{+}$and $\mathrm{CeO}^{+}$can be used to estimate the influence of oxide, and the position of sampling cone can be adjusted to reduce the influence of oxide. At the same time, the presence of oxide and hydroxide can interfere with the determination interfere with ${ }^{58} \mathrm{Ni}$, etc. Therefore, it is necessary to choose the isotope that is not interfered with when the quantitative analysis. There are ${ }^{40} \mathrm{Ar}^{+}$interference ${ }^{40} \mathrm{Ca}^{+}$, ${ }^{58} \mathrm{Fe}$ interference ${ }^{58} \mathrm{Ni},{ }^{113} \mathrm{In}$ interference ${ }^{113} \mathrm{Cd}+$ and so on. Other interference, mainly compound ion interference and double charge ion interference and so on. The composite ions include $,{ }^{40} \mathrm{ArH}^{+},{ }^{40} \mathrm{ArO}^{+}$, etc . For the elements with lower second ionization potential, the existence of double-charged ions will also affect the reliability of the measured values.In this experiment, isopropanol was used for the first time to enhance the sensitivity of iodine signal. The result was better than that reported in literature. The effect of different concentration of methanol, ethanol and isopropanol was compared, the results showed that low concentration of isopropanol had a strong effect on signal sensitizing of ${ }^{127} \mathrm{I}$, and the effect of sensitizing was positively correlated with the concentration of ${ }^{127} \mathrm{I}$ at low concentration $(\leq 4 \%)$. The mechanism may be related to the concentration of alcohol sensitizers and the number of carbon atoms. With the increase of isopropanol concentration, the inhibition of iodine signal is enhanced, which may be due to the energy consumption in decomposition of organic matter, thus reducing the ionization degree of iodine analyte and reducing the signal. The ionization energy of argon is $15.7 \mathrm{ev}$, the ionization energy of iodine is $10.08 \mathrm{ev}$, which is close to the ionization energy of carbon atom is $11.27 \mathrm{ev}$, that is, the ionization of iodine in the plasma is increased by the transfer of electrons from the more ionized iodine atoms to the carbon and carbon polyatomic ion.

The results show that ${ }^{127} \mathrm{I}$ is used as the target element and ${ }^{159} \mathrm{~Tb}$ as the internal standard in the determination of iodine in water samples by ICP-MS, when $1 \%(\mathrm{v} / \mathrm{v}) \mathrm{NH}_{3} \cdot \mathrm{H}_{2} \mathrm{O}$ was used as solvent, $4 \%(\mathrm{v} / \mathrm{v})$ isopropanol as sensitizer, and $2 \%(\mathrm{v} / \mathrm{v}) \mathrm{NH}_{3} \cdot \mathrm{H}_{2} \mathrm{O}$ was used as cleaning solution for more than 180 seconds, the method had high precision and good accuracy. The measured data of iodine content in Lianyungang drinking water source were within the standard range $\left(10 \sim 300 \mu \mathrm{g} \cdot \mathrm{L}^{-1}\right)$, and the measured results (14.01 24.45 $\left.\mu \mathrm{g} \cdot \mathrm{L}^{-1}\right)$ showed that the iodine content in Lianyungang water source was safe and in the low value range.

\section{Conclusion}

The determination of the iodine in water resources can be carried out with an ammonia medium, 4\% (v/v) isopropanol as sensitizer, followed by ICP-MS analysis. The quantification limit of this method is $0.007 \mu \mathrm{g} \cdot \mathrm{L}^{-1}$, which is better than that reported in literature ${ }^{[5,9,17,18]}$. It was shown in this article that adding a certain amount of isopropanol to the solution by ICP-MS can enhance the signal of iodine effectively, better than ethanol as sensitizer reported in literature ${ }^{[21]}$. This method can be used for the determination of trace iodine in water resources. 


\section{Acknowledgments}

This study was supported by the Postgraduate Research and Practice Innovation Program of Jiangsu Province (CXZZ13_0892,China); National Youth Science Fund Project $(\overline{3} 1300652,41706141$, China); the funding of Open subject of Jiangsu Institute of Marine Resources Development; the funding of Jiangsu Ocean University Youth Fund.

\section{Corresponding author}

zhu xiashi, professor,Tel/Fax:+86-514-87975244 E-mail: xszhu@yzu.edu.cn; yojohhit@126.com

\section{References}

1. World Health Organization. (2007) Assessment of Iodine Defificiency Disorders and Monitoring Their Elimination - A Guide for Programme Managers, World Health Organization, Geneva

2. IDDIDD/UNICEF/WHO.(2001) Assessment of iodine deficiency disorders and monitoring their elimination, $W H O$, Geneva.

3. Liu Wei,Yang Hongxia,Li Bing,etc. (2008) Research progress of iodine analysis methods[J].Rock and minerals analysis, 27 (2) :127 136

4. Shen Hongmei, Zhang Shubin, Liu Shoujun, etc. (2007) Study on geographical distribution of high water iodine area and water iodine isoline of high water iodine area in China [J]. Chinese Journal of Epidemiology,26(6): 658 671 .

5. Health Department, Standardization Administration of China.(2007) GB/T 5750-2006 hygienic standard for drinking water [s] . BEIJING: China Standard Press.

6. Wang Haiyan, Liu Liejun, Li Shuhua, etc.. (2007) Study on methods suitable for detection of water iodine in iodine deficiency and iodine excess areas [J]. Chinese Journal of Epidemiology, 26(3) : 333 336

7. Wang fengyun. Discussion on determination method of water iodine $[\mathrm{J}]$. (2008) Journal of Shangqiu Normal University, 24(3) : 83 84

8. Li Jinying, Guo Dongfa, Yao Jijun, etc..(2002) Recent advances in Inductively coupled plasma mass spectrometry (ICP-MS)[J]. Journal of mass spectrometry, 23(3) : 164 179

9. Li Bing, He Hongliao, Shi Shiyun, etc. . (2001) Simultaneous determination of trace iodine, bromine, selenium and arsenic in geological samples by Inductively coupled plasma mass spectrometry [J]. Rock and minerals analysis, 20(3) : 161 166

10. Vanhoe H, Allemeersch F V, Versieck J,et al.Effect of Solvent Type on the Determination of Total Iodine in Milk Power and Human Serum by
Inductively Coupled Plasma Mass Spectrometry [J]. Analyst,118(8):1015

11. Larsen E H,Ludwigsen M B.(1993) Determination of Iodine in Food-related Certified Reference Materials Using Wet Ashing and Determination by Inductively Coupled Plasma Mass Spectrometry [J].J Anal At Spectrom ,1997,12(6):435

12. Cox R J,Pickford C J.(1992) Determination of Iodine-129 in Vegetable Samples by Inductively Coupled Plasma Mass Spectrometry[J].J Anal At Spectrom,7(4):635.

13. Buchert S S A.(1996) Direct Determination of Copper and Iodine in Milk and Power in Alkaaline Solution by Flow Injection Inducrively Coupled Plasma Mass Spectrometry[J].Fresenius J Anal Chem,354:323.

14. Baumann H.(1990) Rapid and Sensitive Determination of Iodine in Fresh Milk and Milk Pewder by Inductively Coupled Plasma Mass Spectrometry [J].Anal Chem,338:809.

15. Wang Xuri, Jia Zhenya, Chen Sheng, etc. . (2015) Determination of bromine and iodine in water by Inductively coupled plasma mass spectrometry[J]. Physical and chemical examination-chemistry, 21(8) : 1187 1190.

16. Cai Xuejian, Fung Permadi, Yang Ling, etc. . (2015) Application of internal standard method in ICPMS[J]. Guangzhou chemical, 43(4) : 156 160

17. Zuo Shumei, Zhang Xiaoyan, Yang Lixue, etc. . (2014) Determination of iodine in drinking water by ICP-MS[J]. Medical Animal Control, 30(12) : 1374 1390

18. Guo Jingjing, Lin Dong,Li Xuran.(2016) Determination of trace iodine ion in water by hydrogen ion chromatography with integrated amperometric detection[J]. Guangdong chemical, 44(16) : $128 \sim 130,169$

19. H. Isnard, A. Nonell, M. Marie, F. (2016) Accurate measurements of 129I concentration by isotope dilution using MC-ICPMS for half-life determination[J].Chartier, Radiochimica Acta, $204: 131 \sim 139$.

20. Liorente L, Gomez M, Camara C.(1997) Improvement of selenium determination in water by inductively coupled plasma mass spectrometry through use of organic compounds as matrix modifiers[J]. Spectrochim. Acta, 52: 1825.

21. Li Bing, Yoon Min. (1995)Study on the enhancement effect of ethanol in Inductively coupled plasma mass spectrometry[J]. Spectroscopy and spectroscopy laboratory, 15:35 